\title{
Hospital School: Investigating the Practical Aspects of Teacher and Parent Training
}

\author{
Olga Ivanova ${ }^{1}$, Marina Shalashova ${ }^{2}$, Elena Tareva ${ }^{3}$ and Oksana Gavrilyuk ${ }^{4, *(D)}$ \\ 1 Department of Pedagogical Technology, Institute of Lifelong Learning, Moscow City University, \\ 119435 Moscow, Russia; ivanova_msc@mail.ru \\ 2 Institute of Lifelong Learning, Moscow City University, 119435 Moscow, Russia; \\ marinashalashova@yandex.ru \\ 3 Institute of Foreign Languages, Moscow City University, 119435 Moscow, Russia; elenatareva@mail.ru \\ 4 Department of Latin and Foreign Languages, Faculty of General Medicine, Professor V.F. Voino-Yasenetsky \\ Krasnoyarsk State Medical University, 660022 Krasnoyarsk, Russia \\ * Correspondence: oksana.gavrilyuk@mail.ru
}

check for updates

Citation: Ivanova, O.; Shalashova,

M.; Tareva, E.; Gavrilyuk, O. Hospital School: Investigating the Practical Aspects of Teacher and Parent Training. Educ. Sci. 2021, 11, 612. http:/ / doi.org/10.3390/

educsci11100612

Academic Editor: John Barker

Received: 22 August 2021

Accepted: 28 September 2021

Published: 3 October 2021

Publisher's Note: MDPI stays neutral with regard to jurisdictional claims in published maps and institutional affiliations.

Copyright: (c) 2021 by the authors. Licensee MDPI, Basel, Switzerland. This article is an open access article distributed under the terms and conditions of the Creative Commons Attribution (CC BY) license (https:// creativecommons.org/licenses/by/ $4.0 /)$.

\begin{abstract}
The purpose of this paper is to investigate the practical aspects of training for parents and teachers of chronically ill children who are under long-term treatment in medical institutions. The paper identifies knowledge, attitudes and practices associated with both formal and non-formal education programs for teachers and parents of children undergoing long-term in-patient treatment. Innovative practices used in Moscow City University are presented, including educational techniques, methods and formats for training teachers and parents of children undergoing long-term treatment together with the results of parent surveys and interviews. The paper describes the benefits of a specially designed program of parent professional retraining to provide tutor support for children with long-term illnesses. Integrating the best informal training practices and formal training modules, this program allows for successful tutoring for children with long-term illnesses.
\end{abstract}

Keywords: hospital school; children with longstanding illnesses; parent training; psychological and pedagogical support; occupational retraining; tutor

\section{Introduction}

According to the Ministry of Health of the Russian Federation, in Russia, about six million children under 18 are treated in hospitals every year. Of these, 200-250 thousand children need long-term (lasting more than 21 days) treatment [1] and, consequently, have to receive their general education in medical institutions. To ensure a high quality of education for children undergoing long-term treatment in medical institutions, an interdepartmental working group of specialists from the Ministry of Health and the Ministry of Education of the Russian Federation was created. In June 2019, this working group published the "Guidelines on organization of training for children who are on long-term treatment and cannot attend educational organizations for health reasons" [1]. To facilitate the introduction of these guidelines, the Ministry of Health of the Russian Federation created a special hierarchical system of medical care, according to which medical organizations or their subdivisions are divided into three levels depending on their main activities and assigned functions [2,3]. According to these guidelines, treatment and training of seriously ill children should be carried out by medical institutions with subdivisions providing high-tech medical care. This decision provided the rationale for the creation of relevant educational structural units at the premises of the leading medical centers and spelled out the rules for the operation of hospital schools in Russia. Specifically, it is indicated that a successful functioning of the hospital schools requires specially qualified professionals who are aware of the specifics of teaching long-term ill children and are able to use technologies of psychological and pedagogical support and follow-up both for children undergoing long-term treatment and their parents. 
Most seriously ill children often have gaps in their knowledge and face a lot of challenges in their learning as a result of prolonged and intermittent absences from school [4]. Therefore, the increasing number of children with longstanding illnesses is a growing challenge both to healthcare and education systems around the globe.

This determines the relevance of the problem of education and personal development of children with longstanding illnesses through creating equal opportunities for successful learning and socialization for every chronically ill child.

In this regard, researchers stress that the educational needs of children with chronic illness can be easily neglected even in an industrialized country [5] and emphasize the importance of special training for hospital teachers and state that there is clearly a need for further investigation on this topic [6].

There is even less research on the education of parents of chronically ill children and their involvement as active agents in the educational process. We believe that an attempt to study this practice can add new knowledge about the training for teachers of hospital schools and parents of children undergoing long-term treatment and can be useful for parents of chronically ill children.

Accordingly, the present study is aimed at investigating the practical aspects of training for parents and teachers of chronically ill children who are under long-term treatment in medical institutions.

The study objectives included:

1. Reviewing the current literature on the issue of training for parents and teachers of chronically ill children who are under long-term treatment in medical institutions;

2. Revealing the most effective techniques used to train parents to support their children with long-term and serious illnesses;

3. Analyzing the practice of training tutors in the medical environment to support chronically ill children;

4. Investigating the practical aspects of parental training through applying a questionnaire for parents of children undergoing long-term hospital treatment.

The main research questions were:

- What practices are relevant to training teachers and parents of children who are undergoing long-term treatment?

- What is the aim of joint training programs for teachers and parents of chronically ill children and what role is played by the parents?

- What problems arise during training teachers and parents of children with long-term illnesses?

- What conditions should be created to ensure successful training for teachers and parents of chronically ill children in the hospital setting?

\section{Materials and Methods}

This article presents the results of a study on the topic "Development and testing of programs of additional education for teachers and parents of children who are on long-term treatment in medical institutions", which was carried out for four years from 2015 to 2019 and continues to the present.

The study used a descriptive research design. Most of the data were obtained through literature review and analysis of the results of selected studies.

According to the first study objective, we reviewed the current literature on the issue of training for parents and teachers of chronically ill children who are under long-term treatment in medical institutions. Specifically, in the course of the research, we analyzed both Russian and international pedagogical, methodological, psychological and medical literature on the research problem (for the period from 2000 to 2021) in order to describe the features of the organization of the educational process in hospital schools and identify the requirements for the competencies of teachers in hospital schools, as well as the inclusion of parents in the educational process. 
The analysis of literature on the research problem was carried out using the method of apperception and the descriptive method. The use of the apperception method made it possible to complete the theory of teaching long-term ill children with new data.

The descriptive method of working with scientific literature made it possible to select relevant articles based on the defined "descripts"- keywords and their combinations. Specifically, we used such descripts as "hospital school", "teachers of hospital schools", "long-term ill children", "training for long-term ill children", "training of teachers of hospital schools", "work with parents of children undergoing long-term treatment" and other relevant keywords and their combinations. Using these descripts, we searched PubMed, Springer, Scopus, Web of Science and Google Scholar databases for full-text English and Russian publications over the past 20 years. Despite a comprehensive search, some publications of recent years may not have been found.

To reveal the most effective approaches and technologies for training teachers and parents to support children undergoing long-term treatment, we performed the content analysis of both national and international educational documents, studied innovative practices of training tutors in the medical environment to support chronically ill children, and investigated the associated processes of changing parents' career path and deterioration of their life quality.

To support our theoretical ideas by evidence from practice, we designed and carried out a special parent questionnaire survey and some interviews for teachers and parents of children who are on long-term in-patient treatment.

The questionnaire survey was carried out in writing, without direct contact between the interviewer and the respondent in order to obtain objective information about the educational background of parents who are on long-term in-patient treatment, as well as about problems and needs of teachers and parents of children undergoing long-term treatment. Moreover, we tried to reveal parents' perceptions about their interaction with their children and their role in their child's further development.

The questionnaire contained both open-ended and closed questions (multiple choice questions). The questions for the interviews were developed in accordance with the objectives of the study. Most of them were open-ended and semi-closed questions.

Applying the obtained data from the interviews and questionnaire survey to the practice of work with parents of children with longstanding and severe diseases in Moscow City Pedagogical University (MGPU), we tried to reveal the most efficient educational techniques, methods and formats for teaching parents of children who are on long-term in-patient treatment. The learning outcomes were evaluated through the use of a series of standard academic achievement tests designated for children of regular schools.

Based on the results of the studies describing the issues of parents' educational needs, problems that arise during their interaction with children, and training management for children with longstanding and severe illnesses, we developed a special program for training parents to support their children with long-term and severe illnesses.

The study was undertaken in accordance with ethical standards provided by the Declaration of Helsinki. All participants gave assent to participate and signed written informed consent. Permission to undertake the study in the hospital schools was also obtained from the respective hospital school authorities. Those who did not fall within the group of the study participants and did not sign written informed consent were all excluded from the study. Both during the questionnaire survey and the interviews, anonymity, confidentiality of information and a friendly atmosphere were ensured.

When developing advanced training programs for teachers of the hospital school, the results of diagnostics of professional competencies, research and analysis of the problems that arise when working with long-term ill children, as well as their educational needs, were used.

The sample included 100 teachers of Moscow school No. 109 working at the premises of the Russian National Medical Research Center for Pediatric Hematology, Oncology, and Immunology named after Dmitry Rogachev and the Russian Children's Clinical Hospital 
named after N.I. Pirogov. The respondents had different lengths of teaching experience (from 3 to 20 years). Most of the study participants (90\%) were female teachers.

A total of 530 parents of children undergoing long-term treatment in hospitals or a rehabilitation course took part in the study of the problems and educational requests of parents (later this group of parents enrolled for professional retraining programs). Of these, $90 \%$ were mothers who were left alone with a sick child, because their husbands left the family after the onset of the child's disease. About $80 \%$ of parent respondents turned out to have higher education, and $20 \%$ had secondary vocational education. Of these, $5 \%$ of parents had a medical education, $25 \%$ an economic education, $45 \%$ a pedagogical education, $15 \%$ an engineering and technical education and $10 \%$ with education in natural science.

The core ideas of the study were determined considering the psychological theory of personal autonomy [7], as well as pedagogical ideas of lifelong learning and a learnercentered approach [8].

\section{Results}

\subsection{Literature Review Results}

Trying to reveal the practices relevant to training teachers and parents of children who are undergoing long-term treatment (research question 1), we discovered that a pivotal role of school and teachers in the education and personal development of children with longstanding and severe illnesses is emphasized in many works [9]. Formal training brings a necessary daily routine into the lives of sick children, motivating them to do different activities that are not related to treatment. Every time a teacher comes to give a lesson, a child needs to get prepared and switch his/her attention from the disease to studying. In these circumstances, to ensure children's switching off from the anxieties associated with their disease, a teacher should be able to create a special atmosphere in the classroom, to interest and motivate children to obtain new knowledge [10,11] and prevent the possible development of anxiety and formation of learned helplessness [12]. Studies suggest that this can be done through the development of children's autonomy, initiative and persistence $[13,14]$. Specifically, it is critical to support children's autonomy, which is reported to be associated with self-development, internal locus of control, empowerment, making decisions and choices, developing individual strategies to meet the goals [15], adapting one's knowledge and competencies to new tasks and developing new skills and competencies throughout the life cycle $[8,16]$. Whereas, autonomous learning is known to be stimulated by autonomous teaching where an autonomous teacher is concerned about what should be changed, why and how to do it better $[17,18]$.

Addressing the problem of education and personal development of chronically ill children, many hospital schools were opened at the premises of large medical research centers in Ireland [19], Britain [20], Australia [20], Russia [21], Germany, Austria [22], USA $[23,24]$ and Finland [25]. This allowed long-term ill children to achieve academic goals to regain their usual socio-pedagogical environment after the end of treatment [21].

In the United States, a novel profession of a life management specialist (LOC) was introduced to manage children's life in a hospital. The first association of specialists in the field of chronically ill children's life management in a hospital was created in 1966 in the USA. Thompson (1981) showed the effectiveness of the introduction of this new profession, including faster recovery and increased satisfaction with treatment [26]. In Scandinavia, a study was carried out to investigate the important aspects of educating school-aged children with chronic diseases during their stay in hospitals [27]. The results showed the importance of special training for professionals who educate families with chronically ill children.

In Spain, a study was conducted to assess the quality of teaching in hospital schools [25]. In this study, the absence of systematic work of teachers with children undergoing treatment was revealed. According to the authors' conclusion, it is necessary to organize special training for teachers to get them prepared to work with chronically ill children. Specifically, the authors emphasized the importance of disease awareness, including the possible 
influence of different diseases on the patient's cognitive processes and their learning. At the same time, this study did not consider the issue of the parental role in education and socialization of chronically ill children [25].

However, parents are considered to be the driving force when teaching children various types of skills. For example, it has been shown that parent-implemented languagebased interventions for children with and without disabilities have had a positive effect on their child's expressive language skills [28].

Hence, parenting a child with a longstanding illness is reported to be challenging because of illness-specific demands [29-31]. Investigating the role played by the parents of chronically ill children in their children's development and trying to define the aim of training programs for parents of chronically ill children (research question 2), we revealed that:

(1) Parents providing tutoring support for their chronically ill children must learn about various issues at the intersection of didactics, psychology and medicine, while they are having the frightening experience of witnessing their child struggle with the illness.

(2) Parents are expected to participate in the development of their child's individual educational route, the latter being defined as a specific combination of components of the educational process, which includes: the formation of basic data about the child, determining the learning goal according to the basic data, selecting the best methods and means to achieve the learning goal, evaluating learning results [32].

(3) Any kind of parental activity should be conducted in accordance with the doctor's recommendations, depending on the duration of hospital stay, the child's knowledge, needs and interests, as well as state of health to determine the amount of the daily load and facilitate their child's adaptation to living with their medical condition.

Considering the above, the development of learner autonomy in chronically ill children requires appropriate family management as autonomous learning is ensured by parental support of their children's autonomy and develops from parents-focused learning, to parent-mediated learning/cooperative learning, to child-determined learning.

This indicates that parents themselves need psychological and pedagogical support in their role as managers for their child's long-term condition and their expertise [33]. This idea is emphasized in many recent pedagogical and psychological studies investigating the issue of training for parents of children with severe illnesses [34-38], including computerassisted training [38,39], telephone coaching [40], as well as parents' perceptions regarding their role in treatment and education of their seriously ill children [41].

There are a number of studies on the problem of training teachers and parents of children with long-term illnesses for psychological and pedagogical support of this category of learners. However, these practices are local and the systematic work on studying this problem is just beginning. Specifically, scientists assume that maintaining consistent parents' contact with teachers (consultants) is critical, since more frequent coach contacts may improve sustainability and effectiveness of training [42]. Drawing on this idea, we suggested that there is a need for joint (for both teachers and parents of chronically ill children) training programs that should be aimed to:

(1) Ensure the development of teachers and parents' psychological and pedagogical assistance skills in accompanying these children in their learning and socialization,

(2) Integrate the opportunities and resources of formal and non-formal education,

(3) Provide parents with the opportunities for changing the profession (professional retraining) for subsequent employment and helping their child and self-realization in a new field of activity.

Investigating the problems that can arise during training teachers and parents of children with long-term illnesses (research question 3 ), we found the works that identify the causes of emotional burnout in teachers in general [43], describe features of the emotional burnout syndrome in teachers working in schools and hospitals [44], and the ways to prevent professional burnout in teachers working with seriously ill children [45]. Therefore, 
recent research mainly concerns the psychological state of teachers and parents of children with long-term illnesses. Only a small number of articles address the issue of training for teachers and parents of children with long-term illnesses in the educational process management. Among them, there are studies that report parent education intervention results and prove the efficacy of Behavior Skills Training (BST) implemented with parents of children with disabilities $[46,47]$.

Also, we revealed the presence of a number of studies on the problem of training teachers for psychological and pedagogical support of children with severe illnesses, including the works describing the experience in teaching parents of children who are on long-term treatment in hospitals. In spite of the fact that these practices are local, the above-mentioned ideas demonstrate the high relevance of a strategy of active parental inclusion in the process of chronically ill children's education. According to our research results, being a key principle of successful chronically ill children's education, this strategy should be based on the following conditions (research question 4):

- Organization of special support for parents, who have seriously ill children under long-term treatment in medical institutions;

- Training of parents on tutor support for children with long-term illnesses;

- Inclusion of parents in the educational process as active and prepared agents.

\subsection{Survey Results and Their Interpretation}

The above-mentioned conditions to ensure successful training for teachers and parents of chronically ill children in the hospital setting should be specified in terms of particular teachers' and parents' tutoring skills. To reveal these skills, the results of our literature review were completed with our survey results concerning the problems that arise during training of children with long-term illnesses (research question 3) and the most efficient forms and methods of working with chronically ill children (research question 4).

According to the survey results, up to $53 \%$ of teachers reported problems in how to help long-term and seriously ill children in stressful situations. About one-third of the respondents (32\%) reported a lack of knowledge in the field of psychological characteristics of long-term and seriously ill children, including the characteristics of their emotionalvolitional, cognitive and communicative spheres. One-fourth of the teachers-participants of the study (25\%) - turned to have problems with the use of ICT in the educational process management. Difficulties in interacting with long-term ill children were emphasized by $15 \%$ of the teachers. The results of the survey among teachers working with children undergoing long-term treatment are presented below in Table 1.

Similarly, the majority ( $92 \%$ ) of parents reported a need to acquire new knowledge (to study their child's psychological characteristics associated with their illness and treatment) and master new skills in order to support their children and help them in recovery and learning. About $66 \%$ of parents emphasized psychological problems in interaction with their child, including difficulties in how to help their child in a stressful situation (53\%); difficulties in breaking free of the feeling of guilt (35\%); a problem in organizing their child's communication with peers (32\%); difficulties in helping their child to cope with fear (30\%); difficulties in interacting in a conflict with a child (36\%); difficulties with helping their child to overcome learning-related challenges $(35 \%)$, as it is demonstrated in Figure 1.

Parents were concerned about problems related to children's adaptation to new circumstances $(30 \%)$, psychological support and empathy $(26 \%)$, overcoming stress in resolving conflicts between partners in family relationships (44\%); building relationships between a sick child and other children (members) in the family (50\%); helping a child to adapt among peers outside the hospital settings (37\%); living a normal life outside of the hospital (53\%); prospects for their child's development $(60 \%)$. 
Table 1. Results of the questionnaire survey of teachers working with children undergoing long-term treatment.

\begin{tabular}{cc}
\hline $\begin{array}{c}\text { Teachers' Skill Gaps Related to Education of Children Undergoing } \\
\text { Long-Term Treatment }\end{array}$ & $\%$ \\
\hline $\begin{array}{c}\text { Knowledge in the field of psychological characteristics of long-term and } \\
\text { seriously ill children }\end{array}$ & 32 \\
\hline $\begin{array}{c}\text { Skills in diagnosing the characteristics of long-term and seriously ill children's } \\
\text { emotional-volitional, cognitive and communicative spheres }\end{array}$ & 25 \\
\hline $\begin{array}{c}\text { Ability to use Information and Communication Technology in managing the } \\
\text { educational process for long-term and seriously ill children }\end{array}$ & 15 \\
\hline $\begin{array}{c}\text { Proficiency in the use of techniques of positive interaction with long-term and } \\
\text { seriously ill children and their parents }\end{array}$ \\
\hline
\end{tabular}

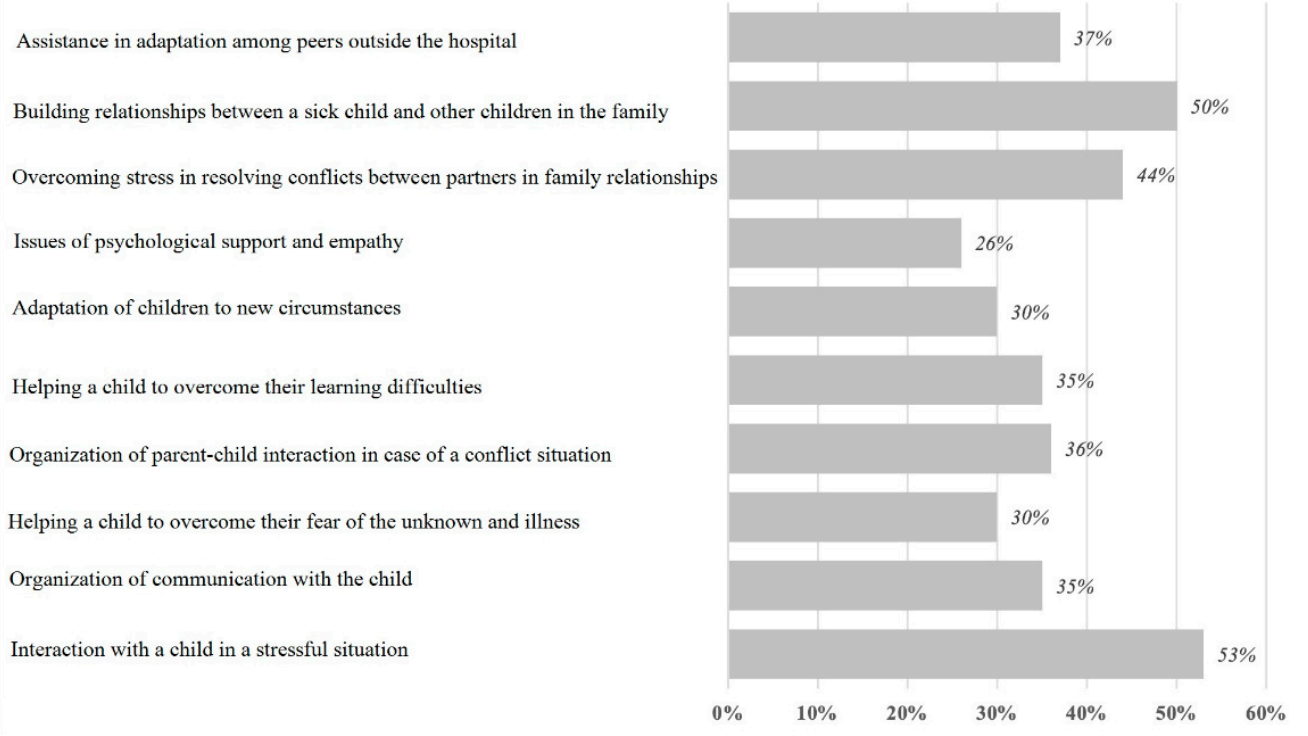

Figure 1. Major concerns of the parents of long-term and seriously ill children (as a percentage of the number of respondents).

The majority of parents reported suffering from a lack of awareness of the psychological, emotional-volitional, cognitive and communicative characteristics of their seriously ill children and the need for support in the organization of the educational process and creating an optimal educational environment for their children.

Among the most frequent answers to the question about the most efficient forms and methods of working with a child, there were: play $(70 \%)$, conversation $(83 \%)$ and collaborative manual work (57\%).

Therefore, supporting sick children who are undergoing long-term treatment in medical hospitals determines the necessity to train tutors from among teachers and parents of children undergoing long-term treatment. In its turn, this necessity requires the development of a system of special parental retraining for this new type of professional activity.

To meet these requirements, Russian pedagogical universities began to train students in master's programs. There is, for example, a new master's program "Tutor support in inclusive education" that has been opened at the Moscow State University of Psychology and Education at the faculty of clinical and special psychology.

The program was meant to train professional competencies for undergraduates that contribute to the development and implementation of technologies for tutoring children with special educational needs.

In 2019, Moscow City Teacher Training University (MCTTU) opened a master's program "Tutoring in education", which was aimed at training specialists in the development 
and use of technologies for tutor support of individual educational programs in the Russian education system. Since 2015, several programs for teachers and parents have been implemented, including:

Professional development program for teachers and parents of long-term ill children "Individual Support for Students in the Educational Process of General Education" (72 h), an additional General Development Program for teachers and parents, without requiring an educational qualification to work with children who are on long-term treatment at medical institutions, "Psychological Support for a Child Who is on Long-Term Treatment at Medical Institutions, in the Learning Process" (50 h) aimed at developing teachers and parents' skills of psychological support of children in their learning.

Interactive lectures, seminars, trainings and practical classes have been organized to develop parents' tutoring skills necessary for managing play, conversation and collaborative manual work. We proposed eight parental general developmental programs: "Life Navigation of a Special Child's Family: Learning to Set and Realize Goals"; "The Educational Space of a Special Child: Learning to Orient and Build"; "The Development of Children with Disabilities"; "Parents' Assessment of Learning Opportunities for a Child with Disabilities"; "A Special Child Parents Legal Orientation"; "Parents of a Special Child: Overcoming Experiences"; "The Family of a Special Child in Society: Barriers and Their Overcoming"; "The Family of a Special Child: Harmonious and Sustainable Relationships".

In 2015-2016, 196 persons received special training at the university, including 116 teachers and 80 parents of children who are on long-term treatment at medical institutions.

Training programs were implemented using distance learning technologies, including the MOODLE distance learning system and the online educational portal http:// uchimznaem.ru/ (accessed on 27 September 2021) ("Teach \& Know"), which hosted training and educational materials and provided a platform for network classes [48].

In 2017, MCTTU teachers developed an elective professional retraining program "Psychology and Pedagogy of Inclusive Education" for parents of children who are on long-term treatment at medical institutions. During the two years of the program implementation, 128 persons were trained, including 89 parents and 29 teachers.

In 2018-2019, MCTTU teachers developed and tested an integrated program of formal and non-formal continuing education for parents on the topic: "Tutoring for Children with Long-Term Illnesses". The goal of the program was to form professional competencies among students, ensuring the implementation of a new type of professional activity in pedagogical support for the implementation of individual educational routes and projects by children, including chronically ill patients. The program was held by the university teachers together with school teachers from economically autonomous structural subdivision "School no 109" of the city of Moscow, as well as volunteers, activists of charitable foundations and non-profit organizations working with long-term ill children and their parents. The program trained 137 parents of children who were on long-term treatment in the Federal Scientific and Clinical Center and Russian children's clinical hospital.

Integrating our research results, this program contained both formal and informal parts and was developed taking into account:

- Children's individual characteristics and capabilities;

- Common problems that teachers and parents experience when interacting with seriously ill children, including teachers and parents' teaching deficits and educational needs;

- The most relevant and efficient practices to training teachers and parents of children who are undergoing long-term treatment;

- Major conditions to ensure successful training for teachers and parents of chronically ill children in the hospital setting.

Since the program was modular and variable (besides compulsory (core) modules, it had a range of optional modules), the trainees could design their own educational route.

Depending on their needs and interests, the trainees could choose not only modules but also individual events (seminars, training, webinars, master classes, video conferences, meetings with interesting people) to be included in the informal part of the program. 
Upon successful completion of this program, each trainee was assigned a "tutor educational qualification", providing the right to engage in tutoring for children with longterm illnesses. The idea was to help parents both find a job in a new profession and provide qualified psychological and pedagogical assistance not only to their child but to other children in a difficult life situation as well. Therefore, mastering this educational program allowed the trainees to ensure successful tutoring for children with long-term illnesses.

\section{Discussion}

We consider that the mission of the hospital school is to ensure the children's personal self-fulfillment and full-fledged medical and social rehabilitation through the creation of an integrated educational environment together with their family members.

In this regard, not only teachers working with children who are under long-term hospital treatment, but also parents should know the psychological characteristics of these children and understand that the disease and medical procedures have a serious impact on the emotional, motivational, and cognitive spheres of every child. Being involved in the development of an individual educational route for their child, parents acquire their first pedagogical experience, which motivates them to start professional retraining programs in pedagogics.

Our analysis of the existing educational models used in different international and domestic hospital schools shows that it is critical to:

- Prioritize the child and his individual learning needs;

- Create different channels of communication between doctors, teachers, children and their parents;

- Provide opportunities not only for academic but also for social and emotional support;

- Use modern technologies to make the children involved in learning and contacting peers [20].

Also, the researchers emphasize the problem of coordination of interaction between all participants in the process. In this regard, Finnish scientists claim that it is the hospital teacher that is responsible for organizing cooperation and coordination (taking on the role of "mediator") between parents of students, doctors, health officials, other teachers of the hospital school and the child's regular school [21].

Compliance with these conditions requires special training of teachers. Consequently, the issue of the need for additional training for regular school teachers to make them suited for work as teachers of hospital schools is being actively discussed. That is why the associations and centers discussed in this paper have designated this task as a priority.

Along with formal training, which is carried out at refresher courses or professional retraining and ends upon obtaining standard form documents, a system of informal training for parents of chronically ill children has been actively developing in Russia. In particular, educational organizations-participants of the innovative platform—“Designing and Implementing an Educational Environment for Children Who are on Long-Term Treatment at Medical Institutions" are regional resource centers that carry out a lot of work to prepare parents for work with long-term ill children.

There are also some positive initiatives reported, particularly, in plans for working with parents placed on the websites of the "Teach \& Know" project satellites in the Khabarovsk territory, Kaliningrad and Voronezh regions, and the city of Krasnoyarsk.

As we revealed, parents can informally improve their professional tutoring skills for long-term ill children by attending seminars, master classes and conferences held by public organizations, and charitable foundations that work with sick children. In this respect, the following features of adult non-formal education should be taken into account:

- Flexibility in mastering the content and the ability to choose the most significant and relevant material;

- Variability and flexibility: the joint construction and completion of the education content, a flexible approach to making the necessary adjustments, and an adequate response to existing requests and needs; 
- Taking into account the individuality and special needs of parents-trainees;

- Emphasis on social support and adaptation in the difficult conditions in which parents of sick children find themselves;

- Extensive use of open education resources (information, tutoring, consulting, remote training, navigation, etc.);

- Using social and cultural resources and going beyond the walls of educational institutions (in a situation with sick children, such access may be virtual, but it is important for parents to know the potential of the network to expand their horizons and educational opportunities when working with children with disabilities);

- Network interaction of various organizations for the implementation of continuing education programs (in this case, we are talking about cooperation between medical and educational organizations in the field of creating an effective system of continuing education for parents of children who are on long-term treatment).

Charitable foundations, nonprofit organizations and associations of specialists provide comprehensive assistance for long-term ill children and their parents; they organize and conduct special training sessions, seminars, consultations and master classes.

A great role in the development of informal continuous education of parents, whose children are in a difficult life situation, including a longstanding severe disease, is played by volunteer organizations. On the website of Volunteers of Russia (https:/ / xn--ppcc-93dhl2 baz3acbc2jodp.xn--p-6mb/) (accessed on 27 September 2021) in the "Education" section, one can find educational courses in different aspects of social volunteering, including work with children who got in a difficult life situation. On the website of VolunteersMedics All-Russian Social Movement (https:/ /xn--ep-e-f4dq2aardoilb5d8h.xn--p-6mb/) (accessed on 27 September 2021) founded in 2013 by activists of Sklif Volunteers project, the comprehensive medical education of different groups of the population is stated as one of the key tasks that the project team tackles. For this purpose, volunteer medical professionals organize major educational work, arrange different enlightening events and deliver both on-site and online courses.

All in all, five educational programs have been developed. In particular, parents whose children are seriously ill for a long time can take a course called Learn Medical English. The educational program has been developed and is being realized by VolunteersMedics All-Russian Social Movement together with the Medical Institute of the Peoples' Friendship University of Russia (RUDN). Special attention in this program is paid to the rules of rendering first psychological and medical aid, the rules of behavior in difficult life situations and also to the basis of healthy lifestyle maintenance and learning the relevant vocabulary in English.

The School of social volunteering founded by the Danilovtsy Volunteer Movement and The Union of Volunteer Organizations and Movements in 2013 is engaged in educating parents whose children undergo continuous treatment in medical institutions of Moscow and other Russian towns and cities. Classes are held both on-site and in online mode using distance learning technologies. The school holds practical seminars, conferences and round tables designed to exchange experience and spread best practices all over Russia.

On the website of The Fund of Combating Leukemia Social Non-Governmental Organization (https: / / leikozn.net) (accessed on 27 September 2021), whose main objective is to help those who suffer from leukemia, there are also materials that can be used to promote informal further education of parents whose children have longstanding severe diseases.

Internet technologies, Web-2.0 services, social services that allow organizing joint teamwork using various resources have come to play an ever-greater role in communications among medical professionals, patients, their relatives and educational workers.

The current wave of school closures caused by the COVID-19 pandemic offered an opportunity for experimentation and for envisioning new models of education both for children with longstanding severe diseases and their parents [49]. In recent times, teaching is often undertaken remotely and on digital platforms, with a significant surge in usage of virtual tutoring, video conferencing tools, or online learning software. In response 
to significant demand, many online learning platforms are offering free access to their service [50,51].

Open group in Facebook social network called A book to help parents whose children suffer from cancer (https:/ / www.facebook.com/photo.php?fbid=2484637028244364\&set= gm.1526650534145706\&type $=1 \&$ theater) (accessed on 27 September 2021) was created by a mother whose child was diagnosed with leukemia in his early childhood. In this group, there are articles, videos, other materials made by specialists, doctors, tutors, educators who work with seriously ill children. This kind of informal further education is becoming more and more requested by the parents of chronically ill children. At present, the group accounts for more than 400 participants who actively communicate with each other discussing a vast range of topics connected with the treatment and radiation of their children.

A Book to Help project (http:/ / onkobook.ru) (accessed on 27 September 2021) united people who publish practical educational supplies for parents on the treatment of cancer in children and fiction books about treatment processes for children. These books are not only for children but also for their parents.

Another example of an efficient resource for informal further education of parents whose children found themselves in a difficult life situation is the work of official resource of Healthy Russia program of the Ministry of Public Health of the Russian Federation, a webportal on healthy way of life called Tak Zdorovo (So Healthy) (http:/ / www.takzdorovo.ru) (accessed on 27 September 2021). Anyone who wishes can take part in online conferences.

Of great importance for informal education of parents whose children suffer from longterm illnesses are mobile apps that are being actively developed at present. An example of such an app is Children in Hospital launched by the World Health Organization. The new Children in Hospital version in Russian is available on Google Play for the Android system. It gives recommendations on the stages of treatment of children in a hospital, everyday care and monitoring, discharge and follow-up observations. This mobile app allows using the recommendations in offline mode. Besides this, it has the following user-friendly functions: interactive links, search, looking through illustrations and other options. Although this app is designed first of all for medical professionals, parents whose children are seriously ill can also find a lot of useful information on their child nursing and care.

Direct Aid Social Charity Organization (DAA) was registered in the Armenian Republic on 7 November 1997. The website of the Organization is http:/ / www.daa.am/ (accessed on 27 September 2021). The main objective of the Organization staff is comprehensive support of children, educators and parents of a hospital school of Arabkir United Medical Center (JMC), the Institute of Children's and Adolescents' Health (ICAH) and the Pediatrics Department of Hematological Hospital [52]. The team members hold consultations for children and families who are facing difficulties in the process of treatment, overcoming diseases and transition to new circumstances. These children and their mothers do not often have sufficient emotional support they need so much. In such cases, the mother often leaves her work, neglects other children in the family and so on to have an opportunity to take care of the seriously ill child. All these factors combined with the child's health problems can produce isolation and cause depression. As the child's illness prolongs, the family might break up. DAA carries out the Mother and Child program. The purpose of this program is to work with women who need support to improve the life quality of their families where a child is seriously ill for a long time. The project started in 2002-2003 with a USAID grant. In 2005 it received a grant from SAAT Swiss Fund. The fund continues to support this program as one of the initiatives of women's strengthening. The pediatric patients' mothers are offered seminars on practical life skills with the potential to get some income from them. Courses in cookery, arts and crafts, computer technologies and foreign languages are available for and popular with not only the families but also medical staff in hospitals. For the years that the project has been functioning, it has undergone some changes determined mainly by the parents' demands. Specifically, seminars on educational games were included in the program. In 2018, the program was used by 1244 persons (chronically ill children, their mothers, brothers and sisters) [53]. 
A great contribution to the development of the education of hospital teachers and parents of long-ill children is made by the Hospital Organization of Pedagogues in Europe (HOPE). This European hospital teachers' association includes hospital teachers from 27 countries [54]. The Russian Federation is represented in the association by teachers of hospital schools participating in the "Teach \& Know" project. The latter is aimed at:

- The creation of a local educational practice of a general education school in the hospital conditions where seriously ill children are being treated for a long time;

- The development of a supportive educational environment in children's hospitals.

Currently, 17 regional platforms have been created and are actively developing within the framework of the "Teach \& Know" project [51].

Teachers, who are members of the HOPE Association, try to provide sick children with a favorable environment and the opportunity to continue their education through school educational activities. HOPE carries out its activity through the organization and holding of various events, seminars, meetings, workshops, conferences, as well as through the publication of newsletters that are distributed throughout Europe. At seminars and workshops, participants actively share their experiences gained in their country in teaching children with long-term and serious illnesses. This organization of open seminars lets more teachers and parents get acquainted with the successful experience in this area, which has been obtained in other countries.

Therefore, the analysis of both foreign and domestic practices of continuing education for teachers and parents of chronically ill children shows that currently a system of nonformal education for teachers and parents of these children is being developed. At the same time, within the framework of formal education teaching is often undertaken remotely and on digital platforms, with a significant surge in usage of virtual tutoring, video conferencing tools, or online learning software since COVID-19 [49]. However, there is limited experience in training and retraining of teachers with long-term ill children, despite the relevance of tutoring for long-term ill children and their parents.

Our results suggest that it is beneficial to train parents of long-term ill children together with hospital school teachers. Specifically, this makes it possible to develop professional competencies in both target groups, promote the exchange of experience of interaction with this type of children, and create a unified team that would contribute to the creation of a developing and supportive environment for children with longstanding diseases. Together with teachers, parents discuss the problems associated with the child's educational needs identification, share their own experiences, search for ways to motivate their child to master the basic educational program, participate in the development of their child's individual educational route, and choose the type of support after discharge from the hospital that could ensure the successful integration of their child into the school at the place of residence.

Moreover, our research results have demonstrated a high relevance of the remote support of parents of children undergoing long-term treatment. The fact is that parents are highly motivated to take part in this type of training but do not have enough free time due to possible changes in the child's physical condition and the need to constantly accompany him in both treatment and training. In this regard, it is important to develop novel high-quality educational content, which could be accessible within $24 \mathrm{~h}$. Such training could be carried out using distance learning forms and the resources of partners who have expert experience in working with this category of both children and parents. In our case, when implementing the program, we used the resource of the educational portal http:/ / uchimznaem.ru / (accessed on 27 September 2021) ("Teach \& Know"), as well as Zoom and MS Teams educational platforms. Also, the "flipped classroom" technique [55] proved to be effective to make the course more practical and interactive.

The use of the resources described in this article and the experience of charitable foundations and non-profit organizations working with long-term ill children and their parents allowed us to ensure parents' autonomy while choosing the most convenient and 
relevant for them non-formal educational resources and handle the situation through making necessary changes in the content and teaching technologies.

Among the limitations of the present study, we can indicate its moderate sample size that included 100 teachers (mainly female subjects) and 530 parents of long-term ill children from Russia. However, the results of this local study, analyzed by the authors through a prism of international research, can be taken into account by different educational stakeholders in other contexts while organizing training for both teachers and parents of children with long-term illnesses.

\section{Conclusions}

The existing foreign and domestic practices of teaching children undergoing long-term treatment indicate that at the present stage, the problem of teaching children with long-term and serious illnesses remains relevant. However, in connection with the emergence of hospital schools, the question arises of training for professional personnel for this type of educational institution, as well as the associated issue of educating parents who need both psychological and pedagogical assistance in accompanying their child and other children in the same life situation. Specifically, there is a gap in didactics concerning relevant full-time and remote techniques for training both teachers and parents of children with longstanding diseases.

The most relevant practices of training for teachers and parents of children who are undergoing long-term treatment include those that provide teachers and parents with psychological and pedagogical assistance in accompanying these children in their learning and socialization, integrate the opportunities and resources of formal and nonformal education and provide parents with the opportunities for changing the profession (professional retraining) for subsequent employment and helping their child and selfrealization in a new field of activity.

Having summarized our study results, we have identified the following types of relevant training practices for teachers and parents of children with long-term illnesses:

(1) Formal training of teachers and parents, which is organized and conducted by specialists of educational institutions that provide additional professional education services; (2) Informal training, including training offered by various organizations and foundations whose main activity is not the provision of additional educational services.

The conducted research allows us to make the conclusion that training for teachers and parents of children who are undergoing long-term treatment should be based on an integrative approach to psychological and pedagogical support of the child and ensure the interaction of teachers and parents as well as the exchange of experience between them. Both parents and hospital teachers should participate in the development of an individual educational route of a chronically ill child in accordance with the doctor's recommendations, depending on the length of the child's stay in the hospital, their level of knowledge, needs and interests, health and well-being status, and determine the amount of daily load.

In other words, our findings suggest that there is a need to integrate the efforts and resources of different agents involved in implementing both formal and non-formal training programs for teachers and parents of children with longstanding diseases. Such programs allow navigating various informal resources, individualizing the learning process, and using the best practices of various institutions.

Therefore, to achieve the success in the training of teachers and parents of children with longstanding diseases, it is necessary to create an open and accessible educational environment based on the integration of formal and non-formal education, as well as the cooperation of the teachers of hospital schools with the involved universities and volunteer organizations.

Within a joint training program for teachers and parents of chronically ill children program, the formal basic and subject-specific training modules were supplemented by the best educational practices covering various aspects of work with long-term ill children. The 
interconnection of the modules of the formal and informal parts of the program ensured the program's integrity, scientific character and practical orientation. Mastering the developed educational program allowed teachers and parents to successfully fulfill the functions of tutoring children with long-term illnesses, provide children with psychological and pedagogical support and accompany them both in a hospital and upon returning home.

The main problems that arose during the implementation of the program included: (1) the problem of the psycho-emotional state of the parents who must be active participants of the pedagogical process of their child medical and social rehabilitation while getting themselves an emotional experience; (2) the problem with the financial situation in families, often resulting in a lack of technical means and poor access to the Internet.

To reduce the risks of these problems' appearance, various pedagogical techniques including those of interactive and dialogical learning, can be used.

To ensure proper technical support of the program implementation, it is important to consider the possibility of temporary provision of technical teaching aids by the hospital school or the manager of the training process (in particular, the university).

In a medical institution, it is advisable to use modular programs to train teachers and educate parents of children with long-term illnesses, which are implemented in full-time form with remote support, so that each of the students can progress at their own pace in mastering their individual program.

Further research is needed to identify effective teaching practices for teachers and parents of children with long-term illnesses and generalize experience in this area. Specifically, the most promising areas of future research include: (1) elaborating individual professional development maps for teachers with consideration for their professional needs and deficits; (2) carrying out an analysis of the employment of seriously ill children's parents after their completion of professional retraining programs, to adjust and improve professional retraining programs; (3) providing a synthesis of teachers' and parents' experience in accompanying seriously ill children in a difficult life situation.

Promoting the wide-scale adoption of the most effective strategies to develop programs and services for both teachers and parents of children with severe diseases, the present research facilitates understanding how teachers and parents develop the expertise to support these children in their education and, therefore, can serve as a roadmap for the future of teaching and parenting policy in relation to work with long-term ill children.

Author Contributions: Conceptualization, O.I.; Investigation, M.S.; Methodology, E.T.; Project administration, O.I.; Resources, O.G.; Writing—original draft, M.S.; Writing—review and editing, E.T. and O.G. All authors have read and agreed to the published version of the manuscript.

Funding: This research received no external funding.

Institutional Review Board Statement: Not applicable.

Informed Consent Statement: Informed consent was obtained from all subjects involved in the study.

Data Availability Statement: The data presented in this study are openly available in the Direct Aid Association annual report published at http:/ / www.daa.am/annual-report.html (accessed on 25 September 2021) [52], in the Mother and Child 2018 Report at http:/ /www.daa.am/assets/mc18. pdf (accessed on 25 September 2021) [53], on the HOPE website at https: / / www.hospitalteachers.eu (accessed on 25 September 2021) [54], and in the "Teach \& Know" Project at https:/ / uchimznaem.ru/ smi/ (accessed on 25 September 2021) [48].

Conflicts of Interest: The authors declare no conflict of interest.

\section{References}

1. Methodological Recommendations on the Organization of Education for Children Who Are on Long-Term Treatment and Cannot Attend Educational Organizations for Health Reasons; The RF Ministry of Education, The RF Ministry of Health: Moscow, Russia, 2019. Available online: https:/ / docs.edu.gov.ru/document/24916df9ea5f575ab603310d687ca89d/ (accessed on 20 September 2021). (In Russian) 
2. Baranov, A.A.; Albitsky, V.Y.; Terletskaya, R.N.; Zelinskaya, D.I. Mnogourovnevaya sistema okazaniya medicinskoj pomoshchi detskomu naseleniyu [Multilevel system of medical care for the child population]. Vopr. Sovrem. Pediatrii 2014, 13, 5-10. (In Russian) [CrossRef]

3. The Strategy for the Development of Healthcare in the Russian Federation for the Long Term 2015-2030. Available online: https:/ / www.rosminzdrav.ru/ministry/61/22/stranitsa-979/strategiya-razvitiyazdravoohraneniya-rossiyskoy-federatsiina-dolgosrochnyy-period (accessed on 22 September 2021). (In Russian)

4. Donnan, B.M.; Webster, T.; Wakefield, C.E.; Dalla-Pozza, L.; Alvaro, F.; Lavoipierre, J.; Marshall, G.M. What about school? Educational challenges for children and adolescents with cancer. Aust. Educ. Dev. Psychol. 2015, 32, 23-40. [CrossRef]

5. Chen, D.F.; Tsai, T.C.; Su, Y.T.; Lin, C.W. Hospital-based school for children with chronic illness in Taiwan. J. Formos. Med Assoc. = Taiwan Yi Zhi 2015, 114, 995-999. [CrossRef] [PubMed]

6. Hopkins, L.; Green, J.; Henry, J.; Edwards, B.; Wong, S. Staying engaged: The role of teachers and schools in keeping young people with health conditions engaged in education. Aust. Educ. Res. 2014, 41, 25-41. [CrossRef]

7. Ryan, R.M.; Deci, E.L. Self-Regulation and the Problem of Human Autonomy: Does Psychology Need Choice, Self-Determination, and Will? J. Personal. 2006, 74, 1557-1586. [CrossRef] [PubMed]

8. Gavrilyuk, O.A. Autonomy as a core value of lifelong learning. J. Sib. Fed. Univ. Humanit. Soc. Sci. 2015, 8, 2283-2290. Available online: http:/ / elib.sfu-kras.ru/bitstream/handle/2311/19879/14_Gavrilyuk.pdf?sequence=3 (accessed on 24 August 2021). [CrossRef]

9. Boles, J.C. School Attendance for Children with Chronic Illnesses. Pediatr. Nurs. 2017, 43, 305.

10. Thies, K. Identifying the Educational Implications of Chronic Illness in School Children. J. Sch. Health 2000, 69, 392-397. [CrossRef]

11. Ivanova, O.A.; Novogilova, N.V. Psihologo-Pedagogiheska Podgotovka Pedagoga dla Raboti s Detmi, Nahodaschimisya na Dlitelnom Lehenii v Medizinskom Uchregdenii. Sbornik Nauchnih Statei po Materialam II Megdunarodnoi Nauchno-Prakticheskoi Konferezii "Rabota s Buduschim v Kontekste Neprerivnogo Obrazovania; Russian Federation: Moscow, Russia, 2019; pp. 137-142. (In Russian)

12. Filippello, P.; Sorrenti, L.; Buzzai, C.; Costa, S. Perceived parental psychological control and learned helplessness: The role of school self-efficacy. Sch. Ment. Health 2015, 7, 298-310. [CrossRef]

13. Volkova, O.V. The methodological principles of medical-psychological-pedagogical correction of learnt helplessness among children having weak somatic health. Psychol. Educ. 2015, 7, 121-132. (In Russian)

14. Filippello, P.; Buzzai, C.; Costa, S.; Orecchio, S.; Sorrenti, L. Teaching style and academic achievement: The mediating role of learned helplessness and mastery orientation. Psychol. Sch. 2020, 57, 5-16. [CrossRef]

15. Noom, M.J.; Dekovic, M.; Meeus, W. Conceptual analysis and measurement of adolescent autonomy. J. Youth Adolesc. 2001, 30, 577-595. [CrossRef]

16. Rychen, D.S.; Salganik, L.H. Key Competencies for a Successful Life and a Well-Functioning Society; Hogrefe \& Huber: Göttingen, Germany, 2003.

17. Sinclair, B.; McGrath, I.; Lamb, T. (Eds.) Learner Autonomy, Teacher Autonomy: Future Directions; Addison Wesley Longman: Harlow, UK, 2000; Available online: https:/ / www.researchgate.net/publication/283998700_Learner_autonomy_and_teacher_ autonomy_Synthesising_an_agenda (accessed on 24 August 2021).

18. Han, L. Teacher's Role in Developing Learner Autonomy: A Literature Review. Int. J. Engl. Lang. Teach. 2014, 1, 21-27. [CrossRef]

19. Kennerk, B. Educating sick children: An Irish hospital school in context, 1900-1980, Hist. Educ. 2019, 48, 356-373. [CrossRef]

20. Hopkins, L.J. Hospital-based education support for students with chronic health conditions. Aust. Health Rev. 2015, 40, 213-218. [CrossRef]

21. Shields, L.; Nixon, J. Hospital care of children in four countries. J. Adv. Nurs. 2004, 45, 475-486. [CrossRef]

22. Weiterführende Ausbildung. Heilstättenschule Wien. Available online: https://heilstaettenschule.schule.wien.at/ausbildungjob / (accessed on 14 May 2020). (In German)

23. Hospital School Program. Children's Hospital of Philadelphia. Available online: https://www.chop.edu/services/hospitalschool-program (accessed on 14 May 2020).

24. McCarthy, A.; Maor, D.; McConney, A. Transforming Mobile Learning and Digital Pedagogies: An Investigation of a Customized Professional Development Program for Teachers in a Hospital School. Contemp. Issues Technol. Teach. Educ. 2019, 19, 498-528.

25. Shaw, S.R.; McCabe, P.C. Hospital-to-school transition for children with chronic illness: Meeting the new challenges of an evolving health care system. Psychol. Sch. 2008, 45, 74-87. [CrossRef]

26. Thompson, R.H. Showing them what you can do: A practical guide for evaluating child life programming. Child. Health Care 1981, 10, 29-36. [CrossRef] [PubMed]

27. Kelo, M.; Eriksson, E.; Eriksson, I. Perceptions of patient education during hospital visit—Described by school-age children with a chronic illness and their parents. Scand. J. Caring Sci. 2013, 27, 894-904. [CrossRef] [PubMed]

28. Roberts, M.Y.; Kaiser, A.P. The effectiveness of parent-implemented language interventions: A meta-analysis. Am. J. Speech-Lang. Pathol. 2011, 20, 180-199. [CrossRef]

29. Jascenoka, J.; Petermann, U.; Petermann, F.; Rissling, J.K.; Springer, S. Kurz-und langfristige Effekte von Elterntrainings bei entwicklungsverzögerten Kindern [Short- and long-term effects of parent training programmes of children with developmental disabilities]. Prax. Kinderpsychol. Kinderpsychiatr. 2013, 62, 348-367. [CrossRef] [PubMed]

30. Law, E.; Fisher, E.; Eccleston, C.; Palermo, T.M. Psychological interventions for parents of children and adolescents with chronic illness. Cochrane Database Syst. Rev. 2019, 4, CD009660. [CrossRef] 
31. Newton, K.; Lamarche, K. Take the challenge: Strategies to improve support for parents of chronically ill children. Home Healthc. Nurs. 2012, 30, E1-E8. [CrossRef] [PubMed]

32. Alisov, E.A.; Ivanova, O.A.; Kunitsyna, S.M.; Surtaeva, N.N.; Frolova, S.L. Information and technological support for inclusive education of people with special educational needs. Int. J. Civ. Eng. Technol. 2018, 9, 993-1001.

33. Smith, J.; Cheater, F.; Bekker, H. Parents' experiences of living with a child with a long-term condition: A rapid structured review of the literature. Health Expect. 2015, 18, 452-474. [CrossRef]

34. Ellis, D.A.; Yopp, J.; Templin, T.; Naar-King, S.; Frey, M.A.; Cunningham, P.B.; Idalski, A.; Niec, L.N. Family mediators and moderators of treatment outcomes among youths with poorly controlled type 1 diabetes: Results from a randomized controlled trial. J. Pediatr. Psychol. 2007, 32, 194-205. [CrossRef]

35. Fisher, H.R. The need of parents with chronically sick children: A literature review. J. Adv. Nurs. 2001, 36, 600-607. [CrossRef]

36. Grey, M.; Jaser, S.S.; Whittemore, R.; Jeon, S.; Lindemann, E. Coping skills training for parents of children with type 1 diabetes. Nurs. Res. 2011, 60, 173-181. [CrossRef] [PubMed]

37. Niebel, G.; Kallweit, C.; Lange, I.; Folster-Holst, R. Direct versus video-aided parent education in atopic eczema in childhood as a supplement to specialty physician treatment. A controlled pilot study [Direkte versus videover-mittelte elternschulung bei atopishchem ekzem in kinderslater als erganzung facharztlicher behandlung: Eine kontrollierte pilotstudie]. Hautarzt 2000, 51, 401-411. [PubMed]

38. Sahler, O.J.Z.; Varni, J.W.; Fairclough, D.L.; Butler, R.W.; Noll, R.B.; Dolgin, M.J.; Phipps, S.; Copeland, D.R.; Katz, E.R.; Mulhern, R.K. Problem-solving skills training for mothers of children with newly diagnosed cancer: A randomized trial. Dev. Behav. Pediatr. 2002, 23, 77-86. [CrossRef]

39. Askins, M.A.; Sahler, O.J.; Sherman, S.A.; Fairclough, D.L.; Butler, R.W.; Katz, E.R.; Dolgin, M.J.; Varni, J.W.; Noll, R.B.; Phipps, S. Report from a multi-institutional randomized clinical trial examining computer-assisted problem-solving skills training for English- and Spanish-speaking mothers of children with newly diagnosed cancer. J. Pediatr. Psychol. 2008, 34, 551-563. [CrossRef]

40. Garbutt, J.M.; Banister, C.; Highstein, G.; Sterkel, R.; Epstein, J.; Bruns, J.; Swerczek, L.; Wells, S.; Waterman, B.; Strunk, R.C.; et al. Telephone coaching for parents of children with asthma: Impact and lessons learned. Arch. Pediatr. Adolesc. Med. 2010, 164, 625-630. [CrossRef]

41. Feudtner, C.; Walter, J.K.; Faerber, J.A.; Hill, D.L.; Carroll, K.W.; Mollen, C.J.; Miller, V.A.; Morrison, W.E.; Munson, D.; Kang, T.I.; et al. Good-parent beliefs of parents of seriously ill children. JAMA Pediatr. 2015, 169, 39-47. [CrossRef]

42. Nelson, K.A.; Highstein, G.R.; Garbutt, J.; Trinkaus, K.; Fisher, E.; Smith, S.R.; Strunk, R.C. A randomized controlled trial of parental asthma coaching to improve outcomes among urban minority children. Arch. Pediatr. Adolesc. Med. 2011, 165, 520-526. [CrossRef]

43. De Stasio, S.; Fiorilli, C.; Benevene, P.; Uusitalo-Malmivaara, L.; Di Chiacchio, C. Burnout in special needs teachers at kindergarten and primary school: Investigating the role of personal resources and work wellbeing. Psychol. Sch. 2017, 54, 472-486. [CrossRef]

44. Alkhateeb, O.; Kraishan, O.M.; Salah, R.O. Level of psychological burnout of a sample of secondary phase teachers in Ma'an Governorate and its relationship with some other variables. Int. Educ. Stud. 2015, 8, 56-68. [CrossRef]

45. Gaidomaschko, I.V.; Katzova, A.P. Kompleksnii podhod k profilaktike professionalnogo vigoraniau pedagogov, rabotayschih s tagelobolnimi detmi. Chelovecheski Cap. 2019, 7, 161-167. (In Russian)

46. Schaefer, J.M.; Andzik, N.R. Evaluating Behavioral Skills Training as an Evidence-Based Practice When Training Parents to Intervene with Their Children. Behav. Modif. 2020. Available online: https://www.researchgate.net/publication/341561725_ Evaluating_Behavioral_Skills_Training_as_an_Evidence-Based_Practice_When_Training_Parents_to_Intervene_with_Their_ Children (accessed on 14 January 2021). [CrossRef]

47. Lequia, J.; Lyons, G.; Machalicek, W. Parent education intervention results in decreased challenging behavior and improved task engagement for students with disabilities during academic tasks. Behav. Interv. 2013, 28, 322-343. [CrossRef]

48. UchimZnaem [Teach \& Know]. Available online: https://uchimznaem.ru/smi/ (accessed on 2 February 2021).

49. Tinubu, A.; Herrera, M. Distance Learning during COVID-19: Seven Equity Considerations for Schools and Districts; Southern Education Foundation: Atlanta, GA, USA, 2020; Available online: https://www.southerneducation.org/covid-19-digital-equity/ (accessed on 20 April 2021).

50. Halpin, P.A.; Lockwood, M.K.K. The use of Twitter and Zoom videoconferencing in healthcare professions seminar course benefits students at a commuter college. Adv. Physiol. Educ. 2019, 43, 246-249. [CrossRef] [PubMed]

51. Darling-Hammond, L.; Flook, L.; Cook-Harvey, C.; Barron, B.; Osher, D. Implications for educational practice of the science of learning and development. Appl. Dev. Sci. 2019. [CrossRef]

52. Direct Aid Association Annual Report Published. Available online: http://www.daa.am/annual-report.html (accessed on 2 February 2021).

53. Mother and Child. 2018 Report. Available online: http:/ / www.daa.am/assets/mc18.pdf (accessed on 2 February 2021).

54. Hospital Organization of Pedagogues in Europe (HOPE). Available online: https://www.hospitalteachers.eu/ (accessed on 1 February 2021).

55. Hew, K.F.; Lo, C.K. Flipped classroom improves student learning in health professions education: A meta-analysis. BMC Med. Educ. 2018, 18, 38. [CrossRef] [PubMed] 